\title{
La Fontaine Fables: a psychopathological approach
}

\author{
A literary review about the irony behind narcissistic and avoidant personality disorders \\ Tiffany Leite-Costa; USF Covelo \\ Ana Miguel; Hospital Vila Nova de Gaia e Espinho
}

ersonality disorders (PD) can be difficult to spot, or at least, difficult to frame. To family physicians this picture is even harder to trace given the rapid 15-minute clinical visit in witch other issues also need to be addressed.

La Fontaine's 1668-1694 twelve books of fables demonstrate the ingenuity to use a now unconventional poetic form to talk about the currently conventional topic of human interaction. Irony is a pre-requirement of the fable since its first appearances in ancient Greece, but it has been well established that the subtile way in witch La Fontaine uses "animals to teach men" is quite unique. The use of irony to spread a message is effective, it involves a conflict between what appears to be real and reality itself. Just by creating this contradictory gap a tension state emerges, this built-up disparity creates a deeper understanding regarding what is told. This literary review arises from another ironic interpretation of the original Lafontainiain irony used to teach morality: the underlying allegoric interpretation of personality disorder traits.

As written by other authors, many variations of ironic tension are possible. There is the "confident unawareness" (pretended in the ironist, real in the victim of irony) as depicted by A. Muecke or more commonly known as the socratic irony, found across the characterization of the envious frog in "The frog that wished to be as big as the ox" (Book I, fable 3) that spots a bull and "smitten with his size/attempts to be as big". The ironic twist of this fable relies on the use of the word "inflated" to describe the frog, a term also used in the Diagnostic Statistic Manual - 5 (DSM-5) and many medical databases to describe narcissistic personality disorder. There's several layers in which this comparison is built, on one hand it talks about an unreasonably unsatisfied frog longing for the ox's idealized appearance, on the other hand there's the never ending pursuit for approval "Sis frog, look here! See me! Is this enough?' and pursuit of gratification and admiration on one's idealized self image or attributes. This conceals an underlying lack of self-esteem with an excessive reference to others for self-definition, causing discomfort and suffering culminating in a fateful burst: "And thus the reptile sits, enraging till she splits".
At the same time another principle of that "confident unawareness" is that someone must seem or be fooled by words and circumstances as explained by the next example. In "The miller, his son and the donkey" (Book III, Fable 1) tension buildup is almost tangible, it tells the story of a man and his son that go to a market to sell their donkey meeting constant criticism about the way they treat the animal and change their behavior according passersby desires. Before the story even starts, the "confident unawareness" is already present by the fact that the story itself is told as a lesson of one poet (François de Malherbe) to another (Honorat de Bieil, seigneur de Racan) when Rancan asks Malherbe for advice on what to do with his life "What shall I do? 'Tis time to choose profession. You know my fortune, birth and disposition". The frustration created by the miller's inability of decision making can resemble the one caused by an avoidant personality disorder. Throughout the poem, the miller is far more preoccupied with other peoples perspectives and inferences then his own, and although these perspectives were indeed negative, he lacked the self-esteem to maintain his decisions "but joke on joke repeated changed his mind" "the miller, much enlightened by this talk, Untied his precious beast and made him walk" feeling shame, inferiority and inadequacy. One could overstep and imagine a life lived on the miller's basis: the detachment on intimate relationships caused by fear of rejection, the withdrawal caused by the panic of being ridiculed, causing avoidance of close relationships, interpersonal attachments, and intimacy, the incapacity of feeling real pleasure or engagement in experiences. After all, did the miller enjoy his ride?

Given the longitudinal nature of personality disorders expression and the sometimes short amount of time available to address them, it becomes important to find instruments to try and understand the global picture of the complex self and interpersonal functioning and empathize with different PD traits so that we can ironically feel "it makes sense".

\section{You can find the fables addressed on} this article here:

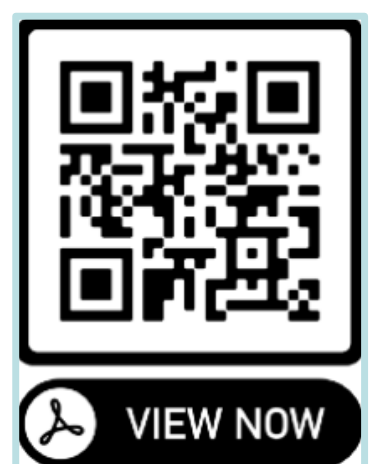

